21. Neumann P, Nordwall A, Osvalder AL (1995) Taumatic instability of the lumbar spine. A dynamic in vitro study of flexion-distraction injury. Spine 20: 1111-1121

22. Neumann P, Osvalder A-L, Nordwall A, Lövsund P, Hansson T (1992) The mechanism of initial flexion-distraction injury in the lumbar spine. Spine 17 : 1083-1090

23. Panjabi MM, Duranceau JS, Oxland TR, Bowen CE (1989) Multidirectional instabilities of traumatic cervical spine injuries in a porcine model. Spine 14: 1111-1115
24. Pearcy M, Portek I, Shepherd J (1984) Three-dimensional $\mathrm{x}$-ray analysis of normal movement in the lumbar spine. Spine 9:294-297

25. Reid OC, Henderson R, Saboe L, Milles IDR (1987) Etiology and clinical course of missed spine fractures. J Trauma 27:980-986

26. Rennie W, Mitchell N (1973) Flexion distraction fractures of the thoracolumbar spine. J Bone Joint Surg Am 55 : 386-390

27. Smith WS, Kaufer H (1969) Patterns and mechanisms of lumbar injuries associated with lap seat belts. J Bone Joint Surg Am 51:239-254
28. Stagnara P, DeMAuroy JC, Dran G, Gonon GP, Costanzo G, Dimnet J, Pasquet A (1982) Reciprocal angulation of vertebral bodies in a sagittal plane: approach to references for the evaluation of kyphosis and lordosis. Spine 7:335342

29. White AA III, Panjabi MM (1990)

Clinical biomechanics of the spine, 2nd eds. JB Lippincott, Philadelphia

\title{
REVIEWER'S COMMENT
}

The more severely ill or injured is the patient, the less time and opportunity will be available for a full radiological examination, and the greater the need for surgeons and radiologists to extract all available information from the scanty initial radiological material, and not to miss unexpected yet essential diagnostic information. The authors

\section{Penning}

University Hospital AZG, Room B 1.08, Hanzeplein 1,

Postbox 30.001, NL-9700 RB Groningen, The Netherlands of this paper remind us of the importance of looking at interspinal distances on AP projections of the spine, and they provide the reader with practical information on how to reliably distinguish between normal and abnormal distances. Their examples convincingly demonstrate that diagnosis of pathologically increased interspinal distance may provide a timely warning of serious disorder of the spine, which may otherwise be overlooked, with sometimes irreversible consequences. 